\title{
EL ORIGEN Y LA EVOLUCIÓN DE LA EXTINCIÓN DEL SALDO INSOLUTO COMO RESULTADO DEL CONCURSO EN EL DISCURSO ANGLOSAJÓN Y SU INCORPORACIÓN EN LA LEGISLACIÓN CHILENA DE QUIEBRAS DE 1929
}

\author{
THE ORIGINS AND EVOLUTION OF THE DISCHARGE OF THE \\ DEBT AS A RESULT OF A BANKRUPTCY PROCEEDING IN ANGLO- \\ SAXON NARRATIVES AND ITS INCORPORATION IN THE CHILEAN \\ BANKRUPTCY ACT OF 1929
}

\author{
Juan Luis Goldenberg Serrano*
}

\begin{abstract}
RESUMEN: Exploraremos las narrativas que llevaron a la incorporación de la extinción de los saldos insolutos al término de los concursos en el mundo anglosajón. El discurso inicial en Inglaterra se centró en la protección de los acreedores, como un incentivo para la cooperación del deudor a efectos de no ser sancionado, alternativamente, con la pena de muerte. La evolución da cuenta de un cambio de paradigma, especialmente en Estados Unidos, fundado en razones humanitarias y en la necesidad de impulsar las economías conscientes de los riesgos del comercio. Es este segundo relato el que fue tempranamente recogido en Chile por medio de la Ley de Quiebras de 1929, aunque cabe destacar que el modelo pecaba de vacíos y contradicciones que, hasta la fecha, no han sido resueltas por el legislador patrio.
\end{abstract}

Palabras clave: extinción del saldo insoluto, quiebra, insolvencia, sobreendeudamiento.

ABSTRACT: We shall explore the narratives that led to the incorporation of the discharge of debts as a result of bankruptcy proceedings in the Anglo-Saxon world. The initial speech in England focused on creditor protection, so discharge was presented as an incentive for the debtor's cooperation for not being punished, alternatively, with the death penalty. The evolution shows a paradigm shift, especially in the United States, based on humanitarian reasons and the need to impulse economies conscient of the risks of trade. It is this second narrative that was early received in Chile in the Bankruptcy Act of 1929, although it should be noted that the model evidenced gaps and contradictions that, to date, have not been solved by the national legislator.

Keywords: discharge, bankruptcy proceeding, insolvency, over-indebtedness.

\section{INTRODUCCIÓN}

En 1936, Georges Ripert refería a un grupo de leyes francesas que habrían consagrado una suerte de "derecho al no pago de las deudas", orientado a la protección del deudor

\footnotetext{
Profesor asociado del Departamento de Derecho Privado de la Pontificia Universidad Católica de Chile. Doctor en Derecho, Universidad de Salamanca. Código Orcid 0000-0003-4671-4730. Dirección postal: Avda. Libertador Bernardo O’Higgins 340. Dirección electrónica: jgoldenb@uc.cl. Este trabajo se inscribe en el proyecto Fondecyt Regular No 1180329.
} 
ante la evidencia de la crisis económica ${ }^{1}$. En el modelo clásico de la deuda, el pacta sunt servanda se erige como un pilar moral y legal basado en la autonomía individual ${ }^{2}$, justificando el trayecto del castigo del incumplimiento desde la pena de muerte, la esclavitud, la prisión por deuda y, por último, la afectación patrimonial universal del deudor ${ }^{3}$. De ahí que en el ordenamiento civil, solo por una insolvencia derivada de accidentes inevitables, el deudor pueda obtener el beneficio de competencia y así retardar el pago hasta mejorar su fortuna ${ }^{4}$. Por ello, llama la atención que, a la época de Ripert, en Chile la Ley No 4.558 (1929) ya había incorporado una medida más extrema: la posible extinción del saldo insoluto de las obligaciones al término de un juicio de quiebra, en un universo en que ello parecía totalmente ajeno a un ordenamiento ceñido a la matriz continental. Solo en este siglo XXI, los relatos de una exoneración inmediata o mediada por un plan de pagos han inundado las discusiones académicas ${ }^{5}$, especialmente como resultado de la crisis sub-prime y el efecto contagio en las economías europeas a mediados de la década pasada. La predilección de la medida del descargue de la deuda (discharge), impulsada por diversas instancias internacionales para aliviar la posición de emprendedores y consumidores sobreendeudados ${ }^{6}$, reposa en un evidente quiebre de paradigma para los sistemas continentales y de ahí las dificultades que ha significado su reconocimiento como medida de "segunda oportunidad".

En este escenario nos interesa repasar el tortuoso camino del reconocimiento del discharge en el Common Law, en particular, en la experiencia inglesa y norteamericana. Las dudas sobre el abuso del sistema, especialmente con la incorporación del concurso voluntario desde la segunda mitad del siglo XIX, y los escasos dividendos obtenidos por los acreedores como resultados de las quiebras, han sido siempre una sombra que ha rondado a todo discurso en torno a la figura. Hoy por hoy, constatados los fenómenos del consumerism y la democratización del crédito $^{7}$, se elevan voces que defienden el modelo de protección del deudor y de la economía en general ${ }^{8}$, viéndolo como un instrumento necesario en una sociedad dependiente de la deuda9. Sin embargo, estas aseveraciones jamás han puesto punto final a la discusión sobre los efectos sociales del discharge, siempre en clave de necesarias restricciones ante la posibilidad de abuso ${ }^{10}$, aun cuando el modelo se sostiene en la medida en la que la responsabilidad limitada del consumidor se transforma en una red de apoyo social (safety $n e t)$, que, en otras latitudes, aún es ofrecida por medio de los Estados de bienestar ${ }^{11}$.

\footnotetext{
1 RIPERT (1936).

2 Huls (2011) p. 75.

3 Para un discurso sobre la evolución de estos modelos, Pérez Ragone (2013).

4 Goldenberg (2017) pp. 239-244.

RAMSAY (2017) pp. 4-5.

6 Por ejemplo, el Fondo Monetario Internacional (Orderly \& Effective Insolvency Procedures. Key Issues, 1999); UNCITRAL (Legislative Guide on Insolvency Law, 2004); el Banco Mundial (Report of the Treatment of the Insolvency of Natural Persons, 2013); y la Unión Europea (entre otras, la reciente Directiva (EU) 2019/1023, de 20 de junio de 2019.

7 Kilborn (2007) p. 52.

8 Ramsay (2017) p. 3

9 Comparato (2018).

10 Skeel JR. (2001) p. 79.

11 Huls (2011) p. 76.
} 
La razón de la búsqueda de los orígenes y la evolución del discharge en los ordenamientos mencionados se encuentra en que no caben dudas de su influencia en el legislador de 1929. Pero lo anterior una vez superado su fundamento original como forma de tutela del acreedor y plasmado ya como un mecanismo de protección del deudor y un medio de fomento al emprendimiento. La propuesta que ofrecemos no se detiene en este punto, sino en apreciar que la adaptación del descargue en el ordenamiento patrio siempre ha presentado algunos vacíos e inconsecuencias, poco apreciables ante el escaso uso de las herramientas concursales dispuestas en dicha ley y en la que la sucedió en 1982 (Ley No 18.175). Problemas que no solo no fueron resueltos por la última reforma concursal (Ley No 20.720), sino exacerbados por motivos que nuestra doctrina y jurisprudencia no han tardado en advertir ${ }^{12}$, haciendo renacer el discurso del abuso que, como se ha dicho, ha perseguido a la figura desde sus orígenes.

\section{LA FORMULACIÓN ORIGINAL Y LA EVOLUCIÓN DEL MODELO INGLÉS: EL DISCHARGE COMO MEDIO DE PROTECCIÓN AL ACREEDOR Y SUS POSTERIORES MATICES}

El título de este apartado parece contraintuitivo porque es difícil entender las razones por las cuales el descargue de las obligaciones podría resultar beneficioso para los acreedores. La explicación se encuentra en la forma en la que se produjo su creación en el reinado de Anna, en la Inglaterra de inicios del siglo XVIII, como una herramienta incrustada en un sistema concursal puramente sancionatorio. Para ello debemos dar cuenta del nacimiento y evolución de las reglas concursales en la isla británica, aunque con el enfoque centrado en el tema que nos preocupa. Al efecto, la primera legislación inglesa que introdujo normas propiamente concursales fue dictada en 1542 [1543] $]^{13}$ ("An act against such men as do make bankrupt”, $34 \& 35$, Henry VIII, c. 4), tomando partido por una visión punitiva de la quiebra. Esta normativa, como se desprende de su título y preámbulo, solo se pretendía abordar aquellas prácticas fraudulentas de quienes consciente y premeditadamente evadían el pago de sus deudas, perjudicando a sus acreedores. Las normativas que le sucedieron en 1570 [1571] (13, Elizabeth I, c. 7), 1604 (1, James I, 15) y 1623 [1624] (21, James I, 19), siguieron basándose en los mismos supuestos fraudulentos, objetivados mediante un creciente listado de los llamados "actos de quiebra" ("acts of bankruptcy"), aumentando también su tono sancionador y, con ello, los poderes asignados a los acreedores respecto a los bienes y a la persona del sujeto infractor ${ }^{14}$. En suma, estas normas concursales se fueron consolidando como mecanismos que buscaban superar las insuficiencias de las herramientas individuales de cobro existentes a la época, identificando a los deudores que utilizaban los

\footnotetext{
12 Caballero (2018); Alarcón (2018).

13 Sobre las dificultades para la indicación de los años de los cuerpos normativos a los que haremos referencia en esta sección, KADENS (2010a) pp. 1236-1237.

14 Especialmente, la Sección VII de la ley de 1623 disponía la posibilidad de que el quebrado (bankrupt) fuese llevado a una picota en un espacio público por un término de dos horas, con una de sus orejas clavadas a dicha picota para luego ser cercenada.
} 
vacíos de dichas legislaciones para esquivar el pago $^{15}$. Por ello solo se advertían como piezas adicionales en la estructura de cobro, sin mayores pretensiones redistributivas ${ }^{16}$, sino como un reflejo de las frustraciones de los acreedores ante la incapacidad de recuperar sus créditos por medio de las cada vez más terribles amenazas ${ }^{17}$.

Toda esta visión justificaba que ninguno de los estatutos mencionados contemplara la extinción de la deuda al término del procedimiento, sino al contrario, como se expresaba en la sección décima de la ley de 1570, los acreedores conservaban los remedios generales para el cobro de la deuda impaga. De ahí que cualquier activo que ingresase al patrimonio del deudor, sin importar cuan temprano o tarde lo hiciera, quedaba expuesto a la incautación de los acreedores. La idea detrás de toda esta estructura, concluye Kadens, era amenazar al deudor con las peores infamias, de modo de dirigir su comportamiento a la cooperación, especialmente en tiempos en que los poderes públicos no se encontraban aun lo suficientemente afianzados para garantizar mecánicas procedimentales que facilitaren la búsqueda, la incautación y el pago ${ }^{18}$. Por ello, estos concursos se formularon con el carácter de involuntarios, en especial si se observa que subyace en ellos la pretensión de protección de los acreedores, sin referencias a una preocupación posición desventurada (forzada o azarosa) del deudor ${ }^{19}$.

Respecto al deudor honesto, se suponía que las reglas generales del cobro de pesos (debt collection) serían suficientes, o, alternativamente, que se podría llegar a un acuerdo colectivo con sus acreedores para aliviar su situación (composition) ${ }^{20}$. Desde el enunciado de la ley de 1542 [1543], y sus revisiones posteriores, quedaba claro que la voz "bankrupt" quedaba delimitada por el tono propio del tratamiento de un "delincuente", de modo que ninguna de sus disposiciones era aplicable a quien solo se encontraba en situación de insolvencia. El problema se encontraba en la delimitación de los supuestos de honestidad y deshonestidad $^{21}$, algo que fue denotando un criticable uso de las herramientas concursales para el ataque a los deudores inocentes ${ }^{22}$. Como las reglas generales de cobro y composición, escasas y dispersas, tampoco favorecían a los acreedores, se fueron buscando formas de ampliar la aplicación de las leyes de quiebras para obtener las ventajas que ellas ofrecían a modo de amenazas para obtener un pronto pago ${ }^{23}$.

Esta línea divisoria, o, al menos, aquella tendiente a un tratamiento más benigno al deudor inocente, fue llenando los discursos de los siglos XVII y XVIII ${ }^{24}$, destacando las

\footnotetext{
5 ТАВв (1991) p. 328.

6 Cohen (1983) p. 6.

7 ТАВв (1991) p. 332.

18 Kadens (2010a) p. 1236.

19 ТАВB (1991) p. 330.

20 KADENS (2010a) p. 1245.

21 Hoppit (1987) p. 20.

22 Kadens (2010a) pp. 1245-1246.

23 De ahí que, como señala JonEs (1979) p. 12, al transformarse la fuga en un "acto de quiebra”, se empezaron a fraguar fórmulas por las cuales los acreedores comprobasen la huida, real o "presunta".

24 Carlos y Lamping (2010) p. 3.
} 
ideas contrarias a la prisión por deudas por parte de Dekker, Petty y Defoe ${ }^{25}$. Así, se fue abriendo un relato en que se suponía que la mayoría de los deudores se encontraban insolventes por meros infortunios, de modo que debían ser protegidos de la sed de venganza y de la avaricia de los acreedores. La imagen del acreedor comprensivo de la situación desgraciada del deudor se fue reemplazando por aquella en que este invocaba la calificación de la conducta como deshonesta para el solo efecto de amenazar con la aplicación de las leyes de quiebra, lo que fue de la mano de la constatación de cárceles abarrotadas de deudores incumplidores en tiempos en que aún se formulaba la necesidad de la prisión por deuda como mecanismo de apremio, más que de sanción ${ }^{26}$. Los reformistas del siglo XVI ya habían propiciado por una nueva mirada, señalando que la reacción en contra de los deudores, incluso defraudadores, debía dirigirse a su patrimonio y no a su persona ${ }^{27}$. Una respuesta que tardó en llegar ante la fuerte noción de prenda corporal que suponía el encarcelamiento, configurando con ello una fórmula para evitar el escape y la pronta entrega del patrimonio para la recuperación de la libertad.

Sin embargo, en el periodo del interregnum, el Parlamento inglés aprobó una serie de normativas de alivio a la posición de los deudores pobres, destacándose la paradigmática Five Pound Act, oficialmente, "An Act for discharging Poor Prisoners unable to satisfie their Creditors", de 4 de septiembre de 1649. Conforme a ella, los deudores prisioneros pudieron recuperar la libertad bajo el juramento de no haber dispuesto fraudulentamente de sus bienes y de que estos no valían más de 5 libras, juramento que podía ser controvertido por sus acreedores hasta 7 años luego de haber sido prestado, para ser nuevamente encarcelado y condenado por perjurio; normativas que luego se repitieron en 1649 y 1652, pero con la especial motivación de liberar las atestadas cárceles, más que, al menos inicialmente, reformular el modo de abordar la situación del deudor insolvente. Estos estatutos se fue-

\footnotetext{
25 Daniel Defoe, reconocido autor de Robinson Crusoe, cayó en quiebra en dos oportunidades y fue sujeto a prisión en 1692 y 1706. En su trabajo "Essay upon proyects" (1697), se refiere al punto de las quiebras, señalando que, si bien las leyes inglesas promueven la misericordia, la lenidad y la libertad, algo de barbarie hay en las legislaciones que permiten la malicia y la revancha del acreedor. Los ensayos de Defoe no cesaron durante la tramitación de la reforma dispuesta por el Parlamento entre 1705 y 1706, a la que nos referiremos más adelante, incluso exigiendo la introducción del discharge. McCord (1996) pp. 170-173.

26 Reconocida en la legislación inglesa para los deudores comerciantes desde 1283 (11, Edward I, Statute of Acton Burnel), contemplando fórmulas de embargo, venta y pago a los acreedores, y estableciendo la posibilidad de prisión ante la inexistencia de bienes muebles para hacer frente a sus obligaciones. Norma complementada en 1285 (13, Edward I, st.3, 1, conocida como "The Statute of merchant") a fin de permitir que, previa certificación del Mayor y del Clerck de la existencia y vencimiento de la obligación, se llevase al deudor a prisión, a costa del acreedor, hasta que se llegase a un acuerdo sobre el pago de la deuda. Para una explicación sobre el funcionamiento original de la prisión por deuda, PUGH (1968) pp. 45-47, y para una crítica sobre la operatoria del modelo, Jones (1979) p. 13. Por su parte, como explica Holdsworth (1966) p. 231, esta idea original fue ampliándose por una serie de acciones y procedimientos a lo largo de los siglos, hasta que "en prácticamente todos los casos, un acreedor podría tomar el cuerpo del deudor en ejecución. Pero, si elegía este remedio, como usualmente lo hacía, no había otros modos de ejecución disponibles para él” (traducción del autor). Especial atención debe darse al estatuto de 1352, dado que, como advierte PUGH (1968) p. 44, se trata de la pieza más relevante en la historia de la prisión por deuda, concediendo al acreedor la posibilidad de conducir al deudor a prisión sin previa tramitación ante un funcionario real. De este modo, se puso a los acreedores al mismo nivel de la Corona en lo que refería al poder de someter el cuerpo del deudor al pago de la deuda.

27 Veall (1970) p. 145.
} 
ron ampliando hasta que en 1671 se aprobó una regla general que, con similar estructura, agregaba que el acreedor que negase la libertad del deudor debía pagar una suma semanal para su mantención en la cárcel, con lo que se limitaban las desgracias por las que el deudor debía pasar para procurarse mantención ${ }^{28}$ (22, Charles II, c. 20) ${ }^{29}$. En 1678, se añadió la liberación de esta clase de deudores si no se comprobaba la existencia de bienes en un plazo de 3 meses, siempre que llevasen a los menos 6 meses en prisión, adeudaren menos de 500 libras, no fuesen extranjeros y hubiesen informado completamente de sus activos y créditos en contra de terceros. En esta última parte, se enuncian los primeros indicios para configurar mecanismos tendientes a la cooperación del deudor basados en beneficios, mas no en tormentos, como había sido la tónica de la época.

En esta línea temporal, recién a inicios del siglo XVIII parece llegarse al convencimiento de que la ley concursal debía efectivamente abordar la situación tanto del deudor deshonesto como del honesto, y otorgar una "zanahoria" al deudor cooperador, que compensara tanto "garrote" 30 que tan pocos resultados había conseguido en las leyes anteriores $^{31}$. De ahí que en el "Act to prevent frauds frequently committed by bankrupts" de 1705 [1706] (IV \& V, Anne, c. 17) la quiebra fraudulenta, entendida como la que revelaba a un deudor reticente y falto de cooperación, empezó a ser castigada con la pena de muerte (considerando al quebrado como un "fellon, without the benefit of clergy") ${ }^{32}$, al tiempo que la norma prodigaba sendos beneficios a quien se entregaba y cooperaba con el esclarecimiento de su situación patrimonial. Por una parte, se le otorgaban 5 libras por cada 100 que se obtuviesen del producto de la realización de los bienes incautados, sin llegar a superar las 200 libras; por la otra, veían extinguidas todas las deudas existentes al tiempo del "acto de quiebra", de manera que ya no podría ser arrestado ni enjuiciado por deudas previas, identificándose aquí el primer reconocimiento del discharge de las obligaciones en el ámbito del derecho concursal ${ }^{33}$.

Para obtener estos beneficios era necesario que el deudor hubiese colaborado compareciendo y entregado toda la información necesaria para el embargo de sus bienes

\footnotetext{
28 Kadens (2010a) p. 1243.

29 Como precisamente se lee de esta norma, muchos de los deudores prisioneros "habían sido víctimas de los tiempos infelices, incluyendo el terrible incendio, sus propios infortunios u otros eventos que los habían puesto en la imposibilidad de pagar a sus acreedores, transformándose en prisioneros sin dar con ello beneficios a alguien, sino una carga para el Reino y una fetidez (incidente inseparable de la extrema pobreza) que podía dar lugar a la pestilencia y a enfermedades contagiosas, de gran perjuicio para el Reino”. Traducción del autor.

30 Kadens (2010a) p. 1252.

31 Aunque debe tenerse presente que esta normativa se pretendía temporal, con eficacia hasta 1709, aunque luego se extendió hasta 1716. Las normas posteriores mantuvieron la idea de la pena de muerte (hasta 1820), mientras el descargue de la deuda pasó a ser un elemento permanente de las leyes concursales solo a partir del "Act to prevent Commiting Frauds by Bankrupts" de 1732 (V, George II, c. 30).

32 Kadens (2010a) p. 1231.

33 No obstante, se debe tener presente la ordenanza de 9 de junio de 1654 del Lord Protector, emitida en tiempos en que se había disuelto el Parlamento. En ella se disponía que los jueces podían ordenar a los acreedores de un deudor prisionero el descargue total o parcial de la deuda, previo a recibir el producto de la realización de sus bienes. Sin embargo, esta herramienta de alivio no duró mucho tiempo, siendo anulada el 26 de junio de 1657 por el Segundo Parlamento del Protectorado.
} 
(disclosure $^{34}$. En el modelo original, la consideración de tal conducta fue entregada a la certificación estricta de la mayoría de los $\operatorname{comisionados}^{35}$ y a la confirmación por parte del Lord Chancellor, el Lord Keeper, los comisionados a quienes se le había confiado el sello real o a dos jueces del Queen's Bench, Common Pleas o Exchequer. Por su parte, los acreedores solo tenían derecho a audiencia, tanto para favorecer o repudiar la mentada calificación, lo que fue prontamente modificado al año siguiente [1707] (5, Anne, c. 22) a efectos de que el certificado de conformidad ("certificate of conformity") fuese aprobado discrecionalmente por cuatro quintas partes de los acreedores, en cabezas y participación del pasivo, como reacción a los abusos reclamados ante el Parlamento ${ }^{36}$. En efecto, la facilidad para el descargue de la deuda en el modelo inicial propició un elevado número de procedimientos (726, entre 1705 y 1706), cifras que descendieron radicalmente con la nueva medida, evidenciado la posibilidad de que deudores honestos no vieran extinguidas sus deudas al término del procedimiento.

Las razones para la incorporación del discharge no se encontraban centradas en las argumentaciones basadas en calificaciones humanitarias ${ }^{37}$, incesantemente propuestas por Defoe, ni en formas de atajar las inescrupulosas acciones de los acreedores denunciados constantemente por este. En primer lugar, la historia nos informa de otras vicisitudes que hicieron necesario un cambio de enfoque a inicios del siglo XVIII, y que ponen una nota de duda sobre las reflexiones relativas a la necesaria limitación de responsabilidad de los comerciantes para el fomento de su actividad, jamás documentada al tiempo de su discusión original ${ }^{38}$. Al contrario, parecen haberse sumado hechos tales como la inestabilidad del comercio de ultramar a partir de la Gloriosa Revolución de 1688; el catastrófico invierno de 1703, en que el río Támesis se congeló, provocando un caos en el transporte y el abastecimiento; la crisis financiera derivada de la sucesión española y la batalla entre las antiguas y nuevas compañías de las indias orientales; como asimismo, la masiva quiebra de Thomas

\footnotetext{
34 Para un mayor detalle de estos requisitos, McCoid (1996) p. 167.

35 SGARD (2013) p. 226, destacando la escasa capacidad jurisdiccional y el carácter transitorio de estas comisiones. El modelo suponía la reunión de comisionados nombrados por el Lord Chancellor para cada caso, existiendo en Londres un listado de abogados y comerciantes que podían integrar los paneles. Por ello, obsérvese que, en Inglaterra, solo en 1831 se crearon tribunales de quiebra (bankruptcy courts) por medio de "An Act to Establish a Court in Bankruptcy" (I \& 2, William IV, c. 56).

36 McCoid (1996) p. 181. Para efectos de evitar fraudes en el otorgamiento de este consentimiento, la ley de 1732, a la que antes hemos hecho referencia, se estableció la nulidad de cualquier acuerdo entre el deudor y los acreedores para incentivar la suscripción del documento.

37 En contra, Levinthal (1919) p. 18, que observa la normativa desde la idea de que en ella se reconoce que los deudores inocentes pueden ser objeto de lástima, aunque luego (p. 19), la advierte como una regla que favorece el comercio en escenarios de riesgo.

38 Cohen (1982) p. 7. Los tiempos de discusión parlamentaria fueron breves: desde el 31 de octubre de 1705, con la primera lectura, hasta la aprobación final el 19 de marzo de 1706. A pesar de la oscuridad en torno al contenido preciso de la discusión, pareciere que la idea del discharge no formaba parte del texto original, y que solo fue incorporado el 4 de febrero de 1706, al admitirse una "cláusula" que permitiese la mejor identificación de los bienes y la prevención del fraude. La referencia se encuentra en el Journal of the House of the Commons, e indica que "that they have Power to receive a Clause, for the better discovery and preventing Frauds committed by Prisoners and Bankrupts, and for the Relief of such Prisoners for Debt, as shall resign their Effects to their creditors". Sobre el particular, Mc CoID (1996) p. 169.
} 
Pitkin, un mercero de lino en Londres ${ }^{39}$, que defraudó a más de 150 acreedores por más de 50.000 libras $^{40}$.

Sin embargo, el mayor debate se produce al graficar la figura como una regla que consagraba una cierta protección al deudor honesto caído en la desgracia de la insolvencia, o si acaso se trata esta de una construcción que solo podemos hacer con la mirada actual ${ }^{41}$. Si bien hay autores que sugieren que la incorporación del discharge obedeció a la constatación de la necesidad de construir con mayor eficacia una sociedad basada en los avances del comercio y, con ello, en el reconocimiento de sus riesgos ${ }^{42}$, esta línea argumental se advierte débil por las razones que ahora indicaremos.

Debe recordarse que, a la época, esta clase de procedimientos eran solamente aplicables a los comerciantes (traders), siempre que debiesen al menos 100 libras a un acreedor, 150 si eran dos o 200 si eran tres o más, y, además, cometieren "actos de quiebra" ${ }^{43}$. Lo anterior quedó especialmente claro a partir de la ley de 1570 [1571] (13, Elizabeth I, c. 7) y se mantuvo hasta 1861, en que las leyes concursales inglesas ampliaron el presupuesto subjetivo de la quiebra (34 \& 35, Victoria, c. 134). De ahí que se comprendan las posteriores explicaciones de Blackwell, para quien las leyes concursales debían basarse en el beneficio del intercambio (trade) y, en consecuencia, no solo debían conceder ciertos privilegios a los acreedores, sino también a los deudores, "tomando en consideración los súbitos e inevitables accidentes a los cuales los hombres de negocios se encuentran expuestos, a condición de que entreguen todos sus bienes para ser divididos entre sus acreedores" ${ }^{24}$. Para estos efectos, se deben tener presente los cambios evidenciados por la economía inglesa desde fines del siglo XVII, con la expansión del comercio ${ }^{45}$, pero también del endeudamiento y de la inversión como motores del nuevo modelo tendiente (aunque más tarde) a la industrialización $^{46}$. Por ello Jones sugiere que la introducción del discharge, aunque más su permanencia, sea también el resultado de la creciente influencia política y social de los comerciantes e industriales ${ }^{47}$.

Empero, de la lectura de las normas de 1705 y 1706 aparece con sugerente claridad que el descargue de la deuda se formuló como un medio (no un fin), promovido para beneficiar a los acreedores en la mejor satisfacción de sus créditos, y de ahí que estuviese supedi-

39 Hoppit (1987) p. 35.

40 Para una detallada revisión del caso, Kadens (2010b).

41 Ya Levinthal (1919) p. 1 daba cuenta de que, para ciertos autores, la primera ley concursal inglesa era la de 1705, precisamente porque ella otorgaba el discharge de la deuda, mientras que las leyes anteriores, especialmente la de 1542 [1543] solo podía ser observada como una regla penal.

42 Норріт (1987) p. 23.

43 Para una descripción de dichos actos en la legislación original y cómo se fueron incorporando algunos supuestos por medio de las reformas de 1604 y 1623, Holdsworth (1966) p. 238, aunque debe destacarse que todas ellas se planteaban a partir del ocultamiento o de la dilación para el ejercicio de los derechos por parte de los acreedores.

44 BlaCKWELL (1766) II, p. 472.

45 MCCOID (1996) p. 166.

46 Rudolph (2013) p. 132.

47 JONES (1979) p. 59. 
tada a la cooperación del deudor ${ }^{48}$, y, luego, a la discrecional aprobación de la mayoría de los acreedores. Por eso Kadens señala que, siendo la primera vez en que la legislación concursal inglesa parecía tomar en cuenta los intereses de los deudores, podría estimarse que ella fue una reacción débil y no realmente intencionada ${ }^{49}$. Como agrega Jones, denotando un escaso aprecio por la figura, es una forma de lograr aquello que los acuerdos (compositions) tan difícilmente conseguían, como era lidiar con la responsabilidad sobreviniente, hasta configurar el concurso como una especie de composición forzada, en que se obtenía la extinción de la deuda (una suerte de remisión impuesta) a cambio de la entrega de todos los bienes del deudor ${ }^{50}$. McCoid parece preferir una posición intermedia, en el sentido que la introducción de la regla del discharge obedecía parcialmente a la atención al deudor honesto, pero desafortunado, como también al propósito de alentar la cooperación con los acreedores para facilitar el éxito del procedimiento ${ }^{51}$. Algo que, sin embargo, se presenta como impreciso si se atiende, por una parte, que la obtención del descargue de la deuda solo podía lograrse en el ámbito de un procedimiento concursal, a la sazón, únicamente involuntario ${ }^{52}$, y, por la otra, porque al introducir implícitamente la distinción entre deudores honestos y deshonestos, la ley no reformó los "actos de quiebra", todos los cuales suponían una cierta reticencia al pago, de manera que la regla presenta una inconsecuencia normativa ${ }^{53}$.

Ahora bien, respecto a los estatutos ingleses posteriores, solo nos interesa destacar algunos aspectos puntuales para los efectos del presente discurso. Lo anterior porque, como veremos, la legislación patria de 1929 parece haber seguido el modelo incorporado en la ley de quiebras norteamericana de 1898, y no el sistema inglés, aun reformulado en varias oportunidades para tal fecha. No obstante, algunas referencias parecen necesarias, precisamente porque al otro lado del Atlántico siempre se tuvo a la vista la evolución de los sistemas concursales de la isla, de modo que alguna interacción es apreciable en relación con la formulación del descargue.

Comenzamos con las normas que fueron tratando de la necesidad de consentimiento de los acreedores para la obtención del discharge, como había quedado fijada en la ley de 1732. En 1842, se dicta un "Act for the amendment of the law of bankruptcy" (5\& 6, Victoria, c. 121), y, con ella, se observa un cambio radical, aunque poco duradero. Al efecto, se declaró expresamente que, a los efectos de la obtención del certificado de conformidad,

\footnotetext{
48 Boshкoff (1982) p. 105; ТАвв (1991) p. 333.

49 Kadens (2010a) p. 1232. McCoid (1996) p. 164 incluso destaca el carácter experimental de la medida, al igual que la pena de muerte impuesta por la norma, en la medida en que inicialmente se dispuso una eficacia transitoria.

50 JONES (1979) p. 50. Sobre este particular, MCCOID (1996) pp. 173-177, vincula las protecciones conferidas a los deudores por el Privy Council y el Chancery y las diversas formas utilizadas para imponer acuerdos (compositions) a los acreedores disidentes como antecedentes a la introducción del discharge en la legislación inglesa. Sobre el carácter experimental de estos medios de coerción, Countryman (1976) p. 227.

51 McCoid (1996) p. 163

52 Tавв (1991) p. 336. Al efecto, SGARD (2013) p. 229, agrega que la inclusión del discharge reforzó la idea de que el procedimiento debía ser involuntario, a efectos de dejar el control en manos de los acreedores.

53 Aquí, el problema particular derivaba del hecho de que el discharge se obtenía respecto a todas las obligaciones preconcursales, entendiendo que la fecha de la quiebra era aquella en la que se había cometido un "acto de quiebra”. HOLDSWORTH (1966) p. 240.
} 
solo se daría audiencia a los acreedores, pero que ya no sería necesaria su firma ${ }^{54}$, y, con ello, bastaba la verificación de los antecedentes por parte de la Corte ${ }^{55}$. Decíamos que este revolucionario sistema, sustentado únicamente en la revisión judicial, duró poco puesto que, si bien sobrevivió la ley de consolidación de 1849 (12 \& 13, Victoria, c. 106), decayó con la de 1869 (32 \& 33, Victoria, c. 71). En su sección 48, se reinsertó la necesidad del consentimiento de los acreedores, atestado por una resolución especial anterior a la petición del certificado por parte del deudor. Adicionalmente, se indicó que el discharge no podría ser otorgado a menos que se comprobase que un reparto de al menos 10 chelines por libra o, en caso de haberse recibido un pago menor, se entendiera que el quebrado no podía ser consignado como responsable de su infortunio y así los acreedores manifestaren su deseo para la emisión de una orden de discharge.

La vuelta final se dio recién en 1883, con la Bankruptcy Act (46 \& 47, Victoria, c. 239), en que, con una regulación bastante más detallada de la materia, se eliminó nuevamente el requisito del consentimiento. El nuevo modelo destacaba porque la solicitud podía ser presentada en cualquier momento por el deudor, debiendo el tribunal instruir al official receiver para la emisión de un informe sobre su conducta y para la citación a una audiencia pública en la que se decidiría sobre la solicitud, previos comentarios del mentado offcial receiver, el trustee y cualquiera de los acreedores. Además de prever múltiples razones por las cuales no procedía la emisión del certificado ${ }^{56}$, la regla destacaba por dar facultades bastante discrecionales al tribunal en el sentido de conferir o no el discharge, o, incluso, condicionarlo en cualquier sentido a eventuales ingresos ulteriores que podrían ser recibidos por el deudor; como asimismo se le facultaba para revocar la orden correspondiente si acaso el deudor no cooperaba con el trustee en todo lo que fuese necesario para la realización y la distribución de los bienes.

Por su parte, respecto a la posibilidad del inicio voluntario del procedimiento, en tierras inglesas ello se admitió para los traders en la ley del 9 de agosto de 1844 ("An act to amend the Law of Insolvency, Bankruptcy, and Execution”, en 7\&8, Victoria, c. 96), con una redacción más clara en la sección XCIII de la ley de consolidación de 1849 (12 \& 13, Victoria, c. 106). La atenuación del fin sancionatorio del concurso se hizo aún más evidente cuando, ampliado el presupuesto subjetivo por medio de la ley de 1861 (24 \& 25, Victoria, c. 134), se permitió el concurso voluntario a todo deudor. Para los efectos de este discurso esta variación es muy trascendente pues el concurso ya no era observado como una herra-

\footnotetext{
54 Así se lee en su Sección 39. Por su parte, la sección CXCVIII de la ley de consolidación de la legislación de bancarrotas de 1849 (12 \& 13, Victoria, c. 106) se mantiene la idea de la sola audiencia de los acreedores, pero ya ni siquiera se indica la innecesaridad de su firma en el certificado de conformidad.

55 La razón, nos informa Countryman (1976) p. 229 se encontraba en la constatación por parte del Parlamento de que el requisito del consentimiento llevaba a su secreta "compra" a los acreedores, a pesar de la ilegalidad de esta clase de acuerdos.

56 Entre ellas destacamos especialmente la continuación del comercio después del conocimiento de la insolvencia; la contratación de deuda sin tener razones para suponer su posibilidad de pago; y haber incurrido en gastos frívolos. Pero también el hecho de tratarse de una medida de única oportunidad, por cuanto se impedía la emisión de un nuevo certificado cuando ya había existido un concurso o convenio; y la cláusula general por medio de la cual se restringía en casos que se le hubiese encontrado culpable de fraude o cualquier infracción fraudulenta.
} 
mienta más dentro del sistema de cobro ${ }^{57}$, significando, junto a la posibilidad del discharge, una técnica para la obtención del beneficio conducente a lo que, hoy por hoy, denominaríamos fresh start.

\section{LA PERMANENTE REFORMULACIÓN EN EL MODELO ESTADOUNIDENSE: EL DISCHARGE COMO MEDIO DE PROTECCIÓN AL DEUDOR}

En el apartado anterior indicábamos que la ley inglesa de 1732 no incidió mayormente en el esquema inglés en el aspecto del que tratamos, sino a efectos de consagrar una detallada regulación del procedimiento y requisitos para la obtención del discharge. Como cuerpo normativo concursal más completo, tal regulación resulta también relevante porque constituye el punto de referencia de la legislación estadounidense, que, a partir de la independencia, prontamente detectó la naturaleza crucial de la quiebra e incorporó la denominada "bankruptcy clause" en su Constitución a efectos de asegurar una normativa federal $(1787)^{58}$. Sin embargo, no fue sino hasta el 3 de abril de 1800 que se logró tal propósito, y, aunque originalmente la ley tendría una vigencia de cinco años, solo la tuvo por algo más de tres ${ }^{59}$. Como esta primera legislación concursal propiamente americana siguió de cerca la estructura de la ley inglesa ${ }^{60}$, no podemos sino replicar las conclusiones a las que llegábamos en el apartado anterior respecto al sentido original del discharge, especialmente si se constata que estamos ante una norma solamente aplicable a los comerciantes (merchants), sin admitir más que concursos involuntarios ante la evidencia de un acto de quiebra. Respecto al modelo de cooperación del deudor, también se conservó la idea de la recompensa para quien se presentase oportunamente ante la comisión y se conformase totalmente a las disposiciones de la ley, como asimismo la extinción de las deudas anteriores a la quiebra, limitándolo en caso de haber obtenido el certificado del que trataremos a continuación con fraude o por haber ocultado bienes por un valor de al menos 100 dólares.

Para estos efectos, la regla también replicaba la necesidad de obtener un certificado (ahora "certificate of discharge") de parte de los comisionados, una vez evidenciado ante el juez de distrito que se efectuó un completo discovery de los bienes y que el deudor se conformó a todas las instrucciones legales. Se destaca, no obstante, que la entrega del certificado requería la suscripción de acreedores que solo representaran dos tercios, en número y valor de la masa pasiva, y la referencia expresa a que la extinción no beneficiaba a los socios del deudor quebrado, ni a otros conjunta o solidariamente responsable de las deudas, siguiendo aquello que ya se había aclarado en la ley inglesa en 1711 (X, Anne, c.15).

\footnotetext{
57 Boshroff (1982) p. 106.

58 Para una referencia a la incorporación del "bankruptcy clause" en la constitución americana, Noel (1919) pp. 67-123.

59 En el tiempo intermedio, nos informa ТАВB (1991) p. 345, varios Estados habían previsto formas de alivio a los deudores encarcelados, como asimismo habían dispuesto reglas puntuales para el discharge de las deudas, en ambos casos, sujeto a dudas de constitucionalidad.

60 Countryman (1976) p. 227.
} 
Sin embargo, fueron precisamente las críticas por la eventual conducción del discharge hacia comportamientos desordenados o irresponsables de los deudores, las que llevaron a la derogación de la ley de 1800, sin que Estados Unidos contase con una nueva legislación hasta $1841^{61}$. Otra razón, agrega Countryman, fue la escasa recuperación de los créditos para los acreedores, especialmente si se considera que, en la mayor parte de los casos, los deudores ya se encontraban en prisión al inicio del procedimiento ${ }^{62}$.

La Ley de 1841 tuvo un tono conscientemente diverso ${ }^{63}$, lo que significó que debieron superarse las reticencias que veían en cualquier fórmula protectora del deudor una promoción de una conducta reprochable. Esta nueva lectura fue consecuencia los reveses la economía norteamericana como efecto del "Pánico del 1837 "64, una recesión que se extendió hasta mediados de la década siguiente. Así, la nueva legislación disponía de un sistema uniforme de quiebras, no solo en relación con el ámbito territorial de aplicación, sino por su disponibilidad para cualquier clase de deudor, merchant or not. La voz bankrupty dejaba de tener el cariz criminal de los antecedentes ingleses, y pasó a designar al procedimiento completo, del mismo modo como la palabra bankrupt simplemente indicaba al deudor que se había visto sometido a este. Adicionalmente, disponía de un concurso voluntario, restringiendo el involuntario únicamente a los comerciantes, circunstancia que denota la distancia entre el instituto concursal con las herramientas de cobro de la deuda, especialmente si se atiende que, conforme al bankruptcy clause constitucional, la potestad legislativa estaba radicada en entes gubernamentales diversos, federales y estatales, respectivamente ${ }^{65}$.

Así, a diferencia del sistema británico, las leyes de quiebra de las colonias americanas se empezaron a formular como mecanismos de tutela, cuyas principales finalidades se encontraban en la protección de la comunidad de los daños que pudiesen devenir de momentos críticos (pérdida de cosechas, guerras, turbulencias financieras y políticas), disminuir las actitudes fraudulentas de los deudores, distribuir la masa activa de forma equitativa de manera de disminuir los efectos en cadena y reconocer intereses humanitarios, como el otorgamiento de una segunda oportunidad y la inembargabilidad de los bienes futuros para la satisfacción de obligaciones pasadas. El punto de partida de este último aspecto se basaba en la ausencia de objetivos económicos o sociales derivados del encarcelamiento o del impedimento de la rehabilitación por parte del deudor insolvente, los que solo le llevaban a convertirse en un lastre de la sociedad ${ }^{66}$.

Reorientadas estas ideas al discharge, resulta que este podía conseguirse mediando la mera solicitud de protección por parte del deudor en el mentado concurso voluntario, satisfaciendo los requerimientos legales (principalmente, el comportamiento bona fide en la entrega de sus bienes y la completa obediencia a la ley), aunque manteniendo la idea de la aprobación (ahora) de la simple mayoría de los acreedores para su obtención. Para estos

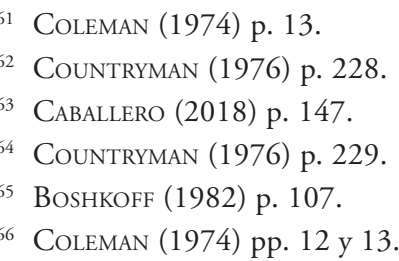


efectos, era necesario que el deudor presentase una solicitud a la corte para la obtención del certificado de discharge, solicitud que debía ser publicada para que cualquier acreedor o interesado presentara objeciones fundadas. De ello se sigue que, a diferencia del modelo anterior, ya no era necesaria una certificación oficial por parte de los comisionados, ni que se requiriese del consentimiento previo de los acreedores, sino su disentimiento causado presentado por escrito ante el tribunal. Por su parte, se establecieron ciertas limitaciones legales para su obtención, como el haber otorgado una ventaja indebida para el pago al acreedor de mala fe (preference), evidencias de fraude, ocultamiento de bienes, desacato a las órdenes e instrucciones judiciales, suposición de deudas inexistentes, uso de fideicomisos (trusts) para fines propios, o, en el caso de mercaderes y otros comerciantes, no haber llevado correctamente sus libros.

Nuevamente, esta ley cayó en el fragor de la discusión política, especialmente ante las voces que afirmaban que el "bankruptcy clause" de la Constitución se refería a mecanismos tendientes a la protección de los acreedores, como los vigentes a la época de la independencia, al tiempo que la ley de 1841, especialmente al admitir el concurso voluntario, era una "ley de insolvencia" más que de bancarrota ${ }^{67}$. La discusión también se centró en las dudas que siempre han perseguido a la figura del discharge en cuanto a la incitación al comportamiento irresponsable de los deudores. Los altos números relativos al uso de los procedimientos (33.739) y a la obtención del discharge (donde solo 765 fueron negados), despertaron nuevos resquemores para los acreedores escasamente pagados ${ }^{68}$, de modo que esta ley tuvo, otra vez, una vida llamativamente breve, siendo derogada el 3 de marzo de 1843.

El tercer intento de ley federal llegó el 2 de marzo de 1867, en un contexto condicionado por los avances que paralelamente se habían presentado en la legislación inglesa y a las duras consecuencias económicas de la guerra civil. En esta normativa, el discharge obtuvo una regulación todavía más detallada (e, incluso, un propio capítulo), evidenciando la creciente importancia que fue adquiriendo con el curso de los años. En este caso, resultado de una negociación entre los intereses de los acreedores y deudores ${ }^{69}$, el sistema suponía que el descargue no se producía de manera automática, sino que requería de una solicitud presentada por el deudor ante la corte, transcurridos 6 meses desde la adjudicación en la quiebra, pero solo hasta un año a contar de tal fecha. Se replicó el modelo anterior, en el sentido de que, sin mediar constatación oficial del cumplimiento de los requisitos, simplemente se notificara a los acreedores para una audiencia en la que se discutiría la eventual (im)procedencia del beneficio previo a la emisión del certificado judicial que, ahora, tenía un texto expreso en la propia ley. Aquí, las causales de improcedencia se extendieron sorprendentemente, obedeciendo a un comportamiento probo del deudor antes y durante el concurso, en un amplísimo catálogo de conductas reprochables que ahora incluían también la falsedad de las declaraciones presentadas ante el tribunal, la falta de cuidado respecto a los bienes que debían entregarse al assignee, la realización de actos revocables (voidable transferences), el pago a alguno de sus acreedores para obtener su favor (preferences), entre

\footnotetext{
${ }^{67}$ Noel (1919) p. 139 у Тавв (1991) p. 351.

68 Countryman (1976) p. 229.

69 ТАвв (1991) p. 355.
} 
otros, destacando la fórmula general de la condena por cualquier infracción a la ley en razón de una acción fraudulenta ${ }^{70}$. Se observa, sin embargo, que el sistema innovó radicalmente en el sentido de que no siempre se requeriría del consentimiento de los acreedores sino a partir del primer aniversario de la ley, de modo que se podría obtener por mero cumplimiento de los requisitos legales siempre y cuando se pagase al menos el 50\% del valor de los créditos verificados. Solo en caso contrario, se necesitaría contar con el consentimiento de la mayoría de los acreedores, tanto en cabezas como en porcentaje del pasivo.

Respecto a la necesidad de contar (o no) con el consentimiento de los acreedores, Tabb explica cómo las normas sucesivas fueron dándole mayor beneplácito a la posición de los deudores: primero, postergando la entrada en vigor de la regla que lo requería (por medio de las leyes de 1867 y 1868); luego, entrada en vigor, aclarando que ella no aplicaba a las deudas anteriores al primero de enero de 1869 (ley de 1870); y, finalmente, eliminado totalmente la necesidad de consentimiento para las quiebras involuntarias y rebajándolo al pago de un 30\% de los créditos verificados en las quiebras voluntarias, o al consentimiento de un cuarto de los acreedores que representaren un tercio del pasivo (ley de 1874) ${ }^{71}$. Para Noel toda esta discusión se soportaba en la constatación de la "compra" del consentimiento de parte de los acreedores ${ }^{72}$. A pesar de todo ello, estas reglas fueron derogadas en 1878, producto de nuevas críticas por parte de los acreedores, que veían en el concurso una respuesta ineficiente, con escasos dividendos, dilaciones y $\operatorname{costos}^{73}$.

En razón de lo anterior, pasó casi un siglo desde la independencia hasta lograr un cuerpo legal estable que abordara la relación entre acreedores y deudores en un escenario de insolvencia: la Bankruptcy Act de 1898, la que, sobre la base de varios compromisos políticos $^{74}$, finalmente incorporó la idea del descargue incondicional de las deudas. Como prontamente notó Newton, uno de los tres pilares sobre los que se construyó la nueva regulación fue "consagrar que los quebrados y los pobres, tuviesen o no bienes, obtuviesen el discharge de sus deudas a un costo nominal, haciendo así innecesario para cualquier hombre en los Estados Unidos seguir cargado con un costal de deudas que no podría pagar"75. Al decir de Noel, el principio de fondo era que ningún deudor deshonesto podría ser aliviado de sus responsabilidades, mientras que el deudor "honesto, pero desafortunado" debía obtener el discharge con toda facilidad ${ }^{76}$.

Aquí debemos detenernos algo más, dado que, como veremos, se trata este del régimen que se acerca al sobreseimiento definitivo extraordinario dispuesto en nuestra ley de 1929. Con la ley de 1898, el concurso se volvió fundamentalmente voluntario, salvo para las corporations (que, a la sazón, ya contaban con el beneficio de la responsabilidad limitada) ${ }^{77}$,

70 Tan extensas eran estas causales de improcedencia del discharge que, como informa Countryman (1919)

p. 230, solo un tercio de los deudores sometidos a concurso obtuvieron el certificado correspondiente.

71 ТАвв (1991) pp. 355 у 346.

72 Noel (1919) p. 153.

73 Countryman (1976) p. 231.

74 Boshroff (1982) p. 108.

75 Newton (1899) p. 287.

76 Noel (1919) p. 159.

77 Goldenberg (2016) pp. 144-149. 
restringiendo asimismo la posibilidad de la quiebra involuntaria. El descargue de la deuda ${ }^{78}$ se obtenía previa solicitud del deudor al tribunal, ahora, en el plazo de un mes a partir de la adjudicación (y hasta 12 meses luego de ella), con la posibilidad de oposición de los interesados únicamente fundado en haber cometido un delito sancionado con la privación de libertad; haber tenido intención fraudulenta en ocultar su verdadera situación financiera o, en vistas de la quiebra, destruir, ocultar o no llevar los libros contables a partir de cuales podría haberse verificado su real condición ${ }^{79}$. Se expresa, nuevamente, que el efecto del discharge no beneficia a terceros, codeudores o garantes de la deuda, ni se extiende a créditos por impuestos, por indemnizaciones por acciones fraudulentas o engañosas, por indemnizaciones por daños a la persona o propiedad de otros (fuesen dolosos o culpables), o resultados de fraude, malversación, apropiación indebida o desfalco, mientras el deudor actuaba como un funcionario (officer) o en cualquier titularidad fiduciaria ${ }^{80}$. Tampoco quedaban extinguidas aquellas deudas que no habían sido reconocidas en el procedimiento en la medida que el acreedor fuese conocido por el deudor, salvo que se comprobase la noticia del primero de la existencia de la quiebra. Mediante esta formulación, bastante más breve que la de su antecedente inmediato, la obtención del discharge se facilitó considerablemente. Además, se liberó de los requisitos del consentimiento de los acreedores o del pago mínimo de un porcentaje del pasivo para su procedencia, al tiempo en que también se cercenó la discrecionalidad de los tribunales en su otorgamiento, de modo que estos solo debían valorar la prueba ofrecida para sus tasadas restricciones ${ }^{81}$. De este modo, el descargue de la deuda se consolidó como uno de sus principios fundantes de la ley de bancarrotas norteamericana, expresado con particular claridad en la paradigmática sentencia de HARDIE V. DRY GOODS CO. ${ }^{82}$.

\section{LA JUSTIFICACIÓN ORIGINAL DEL DISCHARGE EN EL DERECHO CHILENO: UNA INCORPORACIÓN DISRUPTIVA POR MEDIO DE UN MODELO INSUFICIENTE}

La influencia anglosajona en la formulación de la Ley No 4.558, de 1929, parece evidente, aunque no se dejó mayor constancia de ella en su mensaje ${ }^{83}$. Este solo advertía el sentir nacional de la imperiosa necesidad "de reformar la legislación mercantil vigente, para

\footnotetext{
${ }_{78}$ Que ahora aparece formalmente definido en la Sección 1(12) del Bankruptcy Act, como "the release of a bankrupt from all of his debts which are probable in bankruptcy, except such as are excepted by this act".

79 En la reforma del 5 de febrero de 1903 se ampliaron los casos en los que no procedía el discharge, de modo bastante profuso y con gran cercanía al listado de conductas punibles en otras legislaciones de corte continental.

80 Este listado fue complementado por medio de la ley de 2 de marzo de 1917, a efectos de incluir deudas por pensiones de alimentos y sanciones por seducción.

${ }^{81}$ ТАВв (1991) p. 364.

82 HARDIE V. DRY GOODS CO. (1906): "For these considerations, we are disposed to deny that in the present bankruptcy law the discharge of the honest debtor is a mere incident which could have been omitted without impairing its symmetry and efficiency; and, on the contrary, to assert that the release of the honest, unfortunate, and insolvent debtor from the burden of his debts and his restoration to business activity, in the interest of his family and the general public, are the main, if not the most important, objects of the law".

${ }^{83}$ Arcos (1929) p. 118, anotando que el discharge "nos acerca al espíritu de las legislaciones anglo-sajonas, que consideran la quiebra como un estado fisiológico del cual se debe tratar de liberar al fallido en beneficio de él y de la colectividad".
} 
ponerla en armonía con las exigencias de la economía nacional y con la evolución del pensamiento jurídico en los últimos cincuenta años, que se ha acentuado vigorosamente después de la guerra europea de 1914”. No obstante, como se recalcó en el informe de la Comisión Mixta presentado en la sala de la Cámara de Diputados el 3 de enero de 1929, la mirada al mundo sajón fue precisamente la que impulsó el principal cambio de la estructura concursal existente a la fecha, señalando la "conveniencia de someter, absolutamente, a un mismo procedimiento la quiebra del deudor, comerciante o no" ${ }^{\$ 4}$. A fin de entender tal reforma, debe recordarse que esta ley volvió a formular un esquema unitario del concurso ${ }^{85}$, del mismo modo como ocurría desde el Decreto Ley del 8 de febrero de 1837 y hasta la entrada en vigor del Código de Comercio en $1867^{86}$. Más allá de las críticas que concita este planteamiento unitario ${ }^{87}$, se advierte que el principal problema estaba dado por la escasa claridad de las normas concursales aplicables, resultado de una deficiente técnica legislativa del Código de Procedimiento Civil. Con ello, la matriz normativa de los procedimientos fue la quiebra (otrora) mercantil, de modo que las quiebras de los deudores civiles (especialmente, personas naturales) fueron infrecuentes durante toda la vigencia de la Ley No 4.558.

Ahora bien, desde la perspectiva del discharge, hemos aclarado como, a la época de la dictación de la Ley No 4.558, el discurso había avanzado en Inglaterra y Estados Unidos, con diferentes matices, a efectos de consolidar la extinción de las deudas insolutas como un medio de tutela del deudor, y ya no como un impulso a la cooperación en beneficio de los acreedores. La pérdida de la idea del consentimiento de los acreedores como traba a su procedencia, fuese o no mediada por una decisión por parte de los tribunales, es reflejo de la completa desatención a sus intereses puntuales, además de impedir las acciones fraudulentas tendientes a la obtención de su consentimiento. A su vez, la eliminación del requisito de un porcentaje mínimo de satisfacción del pasivo verificado evidenció que la medida debía sustentarse únicamente en promover la recuperación del deudor honesto, sin centrarse en la magnitud de su debacle financiera ni en los resultados de la contribución efectiva del deudor en la búsqueda y realización de sus bienes para el pago de las deudas. Su formulación no tenía un carácter automático, sino mediado por una resolución judicial, previa audien-

\footnotetext{
${ }^{84} \mathrm{Al}$ efecto, se indicó que: "el proyecto ha seguido, en esta parte, el ejemplo de algunas de las más modernas legislaciones que refunden ambas situaciones en un solo procedimiento de liquidación, pero mantienen los principios característicos de la quiebra mercantil y, en lo posible, los peculiares del concurso de acreedores del deudor no dedicado al comercio. No se ha atrevido, como se expresa en el preámbulo a establecer, al igual que en las legislaciones sajonas, la asimilación absoluta de ambos estados, por cuanto ello significaría introducir una modificación demasiado radical en nuestras leyes...". Las actas de las sesiones de la Cámara de Diputados utilizadas para este análisis están disponibles en www.bcn.cl.

85 Palma (1940) p. 9.

86 Goldenberg (2018) pp. 592-599.

${ }^{87}$ Aunque se dio cuenta de que "no se divisa razón alguna atendible que justifique someter a una tramitación distinta la quiebra del deudor, sea o no comerciante [...] El proyecto ha seguido en parte el ejemplo de las legislaciones más modernas y sabias, y acaso también los consejos de la mejor doctrina, refundiendo ambas situaciones en un solo procedimiento de liquidación, pero mantiene los principios característicos de la quiebra mercantil, y, en lo posible, los peculiares del concurso de acreedores del deudor no dedicado al comercio".
} 
cia de los interesados, y las limitaciones que cada norma ofrecía, todas relativas al comportamiento del deudor, para configurar la idea del sujeto "honesto, pero desafortunado" 88 .

Todas estas ideas se encuentran presentes en el artículo 134 de la Ley No 4.558, hasta configurar un "perdón legal" 89 de la deuda respecto al deudor de buena $\mathrm{fe}^{90}$. Al efecto, llama la atención el lenguaje con el que su mensaje da cuenta de lo anterior, puesto que, aun situados en los vestigios de una normativa con el cariz sancionatorio propio de la época, incorporó la posibilidad del discharge expresando lo siguiente: "[...] el sobreseimiento definitivo irá más lejos y extinguirá en ciertos casos las obligaciones del deudor. Esta novedad, que tal vez parezca atrevida e inconsiderada, responde a un sentimiento de justicia y a un propósito de bien público. La quiebra es un juicio que tiende a favorecer los intereses particulares perjudicados y a satisfacer la compensación que debe al crédito público el deudor que ha faltado al cumplimiento de sus compromisos; empero, es prudente, humanitario y justo no extremar estas medidas hasta el exagerado rigor. No siempre el fallido ha llegado a su infortunio merced a la culpa o al fraude; muchas veces han sido casualidad y los reveses del destino los que han arrastrado al incumplimiento de sus obligaciones. Y entonces, su condición reclama benignidad, porque necesita mirar el porvenir con confianza y estímulo para que pueda emprender de nuevo el camino del esfuerzo y quizá del éxito"91.

Mirando con mayor detalle la historia de la ley, se advierte con claridad que no se trató este de un aspecto particularmente debatido, lo que resulta evidente en un contexto en que toda la reforma fue tramitada con inusual premura ${ }^{92}$. Aunque vale la pena arrojar

${ }^{88}$ Honestidad que, en el modelo chileno, queda reconducida a las figuras penales asociadas a la quiebra, distinguiendo, con ello, a los deudores de buena o mala fe. Puelma (1966) p. 204.

89 Carrasco (1963) p. 118.

90 Un punto en que se aprecia una distancia, sin embargo, es en la interpretación dada al tenor literal del artículo 134 de la Ley No 4.558, al tiempo en que Durán (1935) p. 456 y Bravo (1940) pp. 90 y 91, sostiene que, en atención a la referencia a los saldos insolutos, la realización de los bienes en el concurso debía haber permitido un pago parcial de las deudas.

91 Para fines de contexto, un estudio de la visión político-económica del gobierno de Ibáñez, fundadas en las ideas del colectivismo y el nacionalismo, puede consultarse en BRAHM (2018). A su vez, relativo a la mayor intervención estatal en la economía, justificando, entre otros, la creación de la Sindicatura General de Quiebras en reemplazo del sistema de síndicos privados, pueden leerse un número de comunicaciones del presidente Ibáñez a Manuel Oyarzún, quien asumió la primera titularidad de dicho órgano. Ver Donoso (1991-1992) pp. 308 y 318.

92 En la 46a sesión ordinaria de la Cámara de Diputados (26 de septiembre de 1928) se dio cuenta de la propuesta del Ministro de Justicia para la formación de una Comisión Mixta que informase el proyecto de ley, recién presentado por mensaje del presidente Ibáñez del Campo el 22 del mismo mes. Propuesta que fue aprobada, de modo que su informe fue finalmente presentado a la Cámara de Diputados el 3 de enero de 1929 (sesión 88a) (en adelante, el "Informe CM"). El 9 de enero de 1929 (sesión 91a) se propuso y aprobó una forma de tramitación expedita ("como hay urgencia y conveniencia especial en su pronto despacho"), consistente en admitir indicaciones hasta el 12 de enero, para que, luego, una comisión especial evacuara un informe el 15 de enero, que sería considerado como el segundo informe de comisión. Tal comisión especial fue creada por la Cámara de Diputados para el estudio del reporte de la Comisión Mixta antes referida y las indicaciones formuladas por los diputados en la discusión general, comisión que contó con la presencia de Francisco Langlois, Gabriel Palma y Rafael Correa, partícipes de la comisión redactora del primer proyecto. La revisión del informe de la comisión especial solo pudo tener lugar el 22 de enero (sesión 96a), siendo finalmente aprobado al día siguiente (sesión 97a) con algunas modificaciones menores al texto evacuado por dicha comisión (en adelante, el "Informe CE"). Esta redacción, como se indicó en la sesión $101^{\text {a }}$ (31 de enero) fue aprobada sin modificación en el Senado. 
algo de luz sobre el tema a partir de las modificaciones incorporadas al texto del mensaje por medio de las comisiones parlamentarias creadas al efecto ${ }^{93}$, que, por razones de facilidad, ofrecemos en un cuadro comparativo:

el texto de las tablas, siempre a sido en una tipografía distinta al cuerpo de texto de la revista.

\begin{tabular}{|c|c|}
\hline Mensaje & Texto aprobado \\
\hline $\begin{array}{l}\text { Art. 121. El sobreseimiento de la quiebra puede } \\
\text { ser temporal o definitivo. } \\
\text { El sobreseimiento temporal suspende provisio- } \\
\text { nalmente los procedimientos de la quiebra. } \\
\text { El sobreseimiento definitivo pone fin al estado de } \\
\text { quiebra y extingue las obligaciones del deudor. }\end{array}$ & $\begin{array}{l}\text { Art. 128. El sobreseimiento de la quiebra puede } \\
\text { ser temporal o definitivo. } \\
\text { El sobreseimiento temporal suspende provisio- } \\
\text { nalmente los procedimientos de la quiebra. } \\
\text { El sobreseimiento definitivo pone fin al estado } \\
\text { de quiebra9 }{ }^{94} \text {. }\end{array}$ \\
\hline $\begin{array}{l}\text { Art. 127. Se sobreseerá también definitivamen- } \\
\text { te, aun cuando las deudas no se hubiesen al- } \\
\text { canzado a cubrir con el producto de la realiza- } \\
\text { ción de todos los bienes de la quiebra, siempre } \\
\text { que concurran los siguientes requisitos: } \\
1^{\circ} \text {. Que hayan transcurrido cinco años conta- } \\
\text { dos desde que hubiere sido aprobada la cuenta } \\
\text { general del Síndico; y } \\
2^{\circ} \text {. Que la quiebra no haya sido calificada de } \\
\text { culpable o fraudulenta. }\end{array}$ & $\begin{array}{l}\text { Art. 134. Se sobreseerá también definitivamen- } \\
\text { te, aun cuando las deudas no se hubieren al- } \\
\text { canzado a cubrir con el producto de la realiza- } \\
\text { ción de todos los bienes de la quiebra, siempre } \\
\text { que concurran los siguientes requisitos: } \\
1^{\circ} \text {. Que hayan transcurrido cinco años, conta- } \\
\text { dos desde que hubiere sido aprobada la cuenta } \\
\text { general del síndico; y } \\
2^{\circ} \text {. Que, habiendo terminado el procedimiento } \\
\text { de calificación de la quiebra del deudor comer- } \\
\text { ciante, por sentencia ejecutoriada, la quiebra } \\
\text { haya sido calificada de fortuita }{ }^{95} \text { y si se tratare } \\
\text { de un deudor no comerciante, que no haya sido } \\
\text { condenado por alguno de los delitos contem- } \\
\text { plados en el artículo } 466 \text { del Código Penal }{ }^{96} \text {. }\end{array}$ \\
\hline
\end{tabular}

\footnotetext{
93 Aun cuando Palma (1940) p. 9, da cuenta que, desgraciadamente, no se levantaron actas de las citadas comisiones, por lo que sus conclusiones solo son conocidas a partir del debate en la Cámara de Diputados.

94 Redacción del Informe CM. Se observa que la eliminación del efecto extintivo tiene como contrapartida la incorporación de un nuevo inciso en el contexto del "sobreseimiento definitivo extraordinario". Lo anterior tiene sentido porque los supuestos de "sobreseimiento definitivo ordinario" conllevaban otras formas de extinción, sea mediante el pago o la remisión de la deuda, o, en otros casos, no podían implicar la extinción de los créditos cuando su pago quedaba sujeto a caución.

95 Con un grosero error, el Informe CM, redactó el segundo requisito señalando lo siguiente: "20. Que, habiendo terminado el procedimiento de calificación por sentencia ejecutoriada, la quiebra haya sido calificada culpable o fraudulenta". Lo anterior fue corregido por medio del Informe CE, indicando, en esta parte: "2.o Que, habiendo terminado el procedimiento de calificación de la quiebra del deudor comerciante, por sentencia ejecutoriada, la quiebra haya sido calificada de fortuita".
}

96 Redacción del Informe CE. 


\begin{tabular}{|c|c|}
\hline & $\begin{array}{l}\text { El sobreseimiento de que trata este artículo ex- } \\
\text { tingue, además, las obligaciones del fallido por } \\
\text { los saldos insolutos de sus deudas anteriores a } \\
\text { la declaración de quiebra, sin perjuicio de dis- } \\
\text { tribuirse entre los acreedores el producto de los } \\
\text { bienes adquiridos con posterioridad y ya ingre- } \\
\text { sados a la quiebra con arreglo al artículo } 62 \text { de } \\
\text { la presente ley }{ }^{97} \text {. }\end{array}$ \\
\hline $\begin{array}{l}\text { Art. 128. La solicitud de sobreseimiento defini- } \\
\text { tivo se notificará por avisos. } \\
\text { Dentro del término de cinco días siguientes a la } \\
\text { notificación podrán deducirse oposiciones, las } \\
\text { que se tramitarán como incidente entre el deu- } \\
\text { dor, el Síndico y el opositor. }\end{array}$ & $\begin{array}{l}\text { Art. 135. La solicitud de sobreseimiento defini- } \\
\text { tivo se notificará por avisos. } \\
\text { Dentro del término de cinco días siguientes a la } \\
\text { notificación, podrán deducirse oposiciones, las } \\
\text { que se tramitarán como incidente entre el deu- } \\
\text { dor, el síndico y el opositor. La resolución será } \\
\text { apelable en ambos efectos }{ }^{98} \text {. }\end{array}$ \\
\hline $\begin{array}{l}\text { Art. 131. El sobreseimiento no exime al Síndico } \\
\text { de la obligación de seguir adelante el juicio de } \\
\text { calificación de la quiebra. }\end{array}$ & $-\mathbf{- -}^{99}$ \\
\hline $\begin{array}{l}\text { Art. 181. La quiebra puede ser fortuita, culpa- } \\
\text { ble o fraudulenta. }\end{array}$ & $\begin{array}{l}\text { Art. 187. La quiebra del deudor comerciante, } \\
\text { puede ser fortuita, culpable o fraudulenta }{ }^{100} \text {. }\end{array}$ \\
\hline --- & $\begin{array}{l}\text { Art. 205. Las disposiciones del presente Títu- } \\
\text { lo no se aplicarán al deudor no comerciante, } \\
\text { quien quedará sujeto a las prescripciones del } \\
\text { Código Penal. } \\
\text { Si la quiebra del deudor no comerciante fue- } \\
\text { re declarada por la causal del número } 3^{\circ} \text { del } \\
\text { artículo } 37 \text { de esta ley, el Tribunal, de oficio, } \\
\text { lo comunicará al juez del crimen para que ins- } \\
\text { truya el correspondiente sumario o procederá a } \\
\text { formarlo si ejerciere, también, jurisdicción en } \\
\text { lo criminal. } \\
\text { Se hacen extensión a este caso las disposicio- } \\
\text { nes de los artículos } 194 \text { a } 197 \text { inclusives, en } \\
\text { cuanto sean aplicables }{ }^{101} \text {. }\end{array}$ \\
\hline
\end{tabular}

Sobre el particular, se observan los siguientes aspectos. El primero, relativo a la distinción para la obtención del discharge entre deudores comerciantes o civiles, cuestión que no se presenta en los precedentes anglosajones. Al efecto, en el Informe CE se destacó que, si bien se pretendía un sistema generalmente unitario, se "[...] ha desechado, sin embargo, la idea de equiparar para los efectos de la calificación de la quiebra y de las penas consi-

\footnotetext{
97 Redacción del Informe CM.

98 Redacción del Informe CM.

99 Regla eliminada por el Informe CM.

100 Redacción del Informe CE.

101 Redacción del Informe CE.
} 
guientes establecidas en este proyecto, al deudor comerciante y al no dedicado al comercio. [...] el deudor no dedicado al comercio, no puede tener el volumen de las obligaciones de un comerciante y, generalmente, no goza de crédito personal sino que en forma muy limitada y habida consideración de su fortuna [...] Para el deudor no comerciante, la ley contempla hoy día sanciones en casos calificados, como son las consignadas en el artículo 466 del Código Penal"102. Y, con ello, se aprobó la indicación planteada por el diputado Moreno, eliminando a los deudores no comerciantes de las reglas relativas a la calificación de la quiebra ${ }^{103}$, debiéndose modificar el texto original relativo al sobreseimiento definitivo extraordinario a fin de distinguir, en su segundo requisito, la situación del deudor comerciante y no comerciante, refiriendo a las figuras penales que a cada cual resultaran pertinentes.

En lo que nos interesa, tal reformulación tiene interés por los siguientes puntos: (i) a diferencia de los delitos de la quiebra incorporados en la Ley No 4.558, el supuesto típico del artículo 466 del Código Penal no requería del inicio de un procedimiento concursal para su procedencia, aunque si la comprobación de la insolvencia, real o ficta, del deudor ${ }^{104}$. Así, al menos del modo planteado por dicha redacción, el descargue de la deuda se obstruía por la existencia de condenas no asociadas con la quiebra en cuestión, lo que no hubiese ocurrido en el caso del deudor comerciante ${ }^{105}$; y (ii) la honestidad del deudor solo refería, en este caso, a comportamientos previos al concurso, especialmente si se contrasta con los efectos del desasimiento producto de la dictación de la sentencia declaratoria de quiebra (artículo 61), restando la idea de cooperación que permeó siempre los antecedentes anglosajones y que, indirectamente, se aplicaba en la ley chilena a los deudores comerciantes, al observar la tipificación del delito de quiebra culpable dispuesto en el art. 189, núm. 5 ("negar a dar al síndico explicaciones sobre sus negocios"). Con ello, la valoración de la buena o mala fe del sujeto se presentaba de modo diverso en atención a la habitualidad (o no) de la ejecución de actos de comercio, aunque siempre utilizando las figuras penales para un doble castigo, penal y civil, calificando este último por la subsistencia del estado de quiebra hasta la (improbable) obtención del sobreseimiento definitivo ordinario ${ }^{106}$.

En segundo lugar, a diferencia de lo previsto en el texto inicial, en el caso de los comerciantes no bastaba que la quiebra no hubiese sido calificada como culpable o fraudulenta, sino que requería de una sentencia ejecutoriada que la declarase fortuita. Sin perjuicio de que hemos dado cuenta que, tal vez, dicha formulación proviene de la necesaria corrección que debió hacerse en la Cámara de Diputados al texto emanado del Informe CM, la nueva redacción parecía atender a evitar la obtención del descargue de la deuda antes del

\footnotetext{
102 Por ello, Carrasco (1963) p. 102, sostiene que el modelo chileno era intermedio (entre el anglosajón y el francés), puesto que el "legislador ha creído que nuestro país aún no se encuentra preparado para una reforma de tal carácter”, aunque la estima previsible para un futuro próximo. Algo que, como sabemos, nunca ocurrió, hasta la completa fractura del sistema unitario en la Ley No 20.720, de 2014.

103 Bravo (1929) pp. 129-131; Carrasco (1963) p. 118.

104 Sobre este punto, Puga (2016) pp. 135 y 136.

105 En contra, Bravo (1940) p. 93.

106 El punto es criticado por PUGA (1999) p. 680, al aseverar que la técnica legislativa utilizada en Chile termina beneficiando a quien, a pesar de no haber incurrido en conductas punibles, sea culpable de su insolvencia en el plano civil.
} 
término del procedimiento de calificación, si acaso este se hubiese extendido más allá de los 5 años desde la cuenta del síndico. La nueva redacción, en cambio, producía el siguiente efecto: al tenor del artículo 194, declarada la quiebra del deudor comerciante, el tribunal debía remitir los antecedentes al juez del crimen para que este instruyese sumario, a fin de indagar si el fallido o cualquiera otra persona eran responsables de algún delito de la quiebra. De tal modo, el único modo de obtener la declaración del carácter fortuito de la quiebra era mediante el sobreseimiento definitivo (en sede penal) de la causa (artículo 198). De este modo, a diferencia de lo que ocurría en los antecedentes anglosajones, la reconducción de la ponderación del carácter "honesto" del deudor a las normas penales implicaba que se debe haber necesariamente seguido todo el juicio de calificación penal, deteniendo, o, al menos, dilatando con ello, la obtención del discharge. Así, se produce una nueva diferencia con el caso del deudor civil, que simplemente requería la falta de condena, precisamente por la ausencia de un expediente de calificación ${ }^{107}$, sin resolver qué ocurriría en caso de haberse iniciado una persecución penal en razón del artículo 466 del Código Penal o, incluso, de haberse obtenido una condena luego de los 5 años desde la cuenta final del síndico ${ }^{108}$.

Indicábamos que la forma en que quedaron redactadas estas normas no solo da cuenta de ciertas inconsistencias, sino también de vacíos, especialmente si se compara con los antecedentes anglosajones. De ahí se concluye que el régimen jurídico del discharge siempre se ha presentado en nuestro país de modo incompleto, lo que provino del trasplante parcial de una figura que, a la sazón, llevaba ya doscientos años de historia legislativa, con múltiples formulaciones de prueba y error. A continuación, destacamos aquellos aspectos que nos parecen más complejos para una correcta comprensión de los alcances de la figura.

Por una parte, nada se indica respecto a alguna suerte de catálogo de deudas que quedarían al margen del efecto extintivo de las obligaciones, cuestión que, a la época, había dado lugar a recientes modificaciones en el sistema estadounidense. Aquí, el vacío se presenta porque el ordenamiento priva de una calificación sobre la relevancia de ciertas políticas públicas subyacentes en el tratamiento de las obligaciones, tanto en lo que se refiere a sus fuentes, como a sus modos de extinción. La calificación de una deuda como "non-dischargable" alude a una ponderación de los bienes jurídicos protegidos, los que, en ciertos casos, pueden estimarse superiores a los fines perseguidos por políticas de fresh start ${ }^{109}$, dando cuenta de los contornos de la figura de modo más preciso. Estos listados, por supuesto, están expuestos a revisión, y pasaron desde la mera indicación de ciertos créditos públicos (especialmente, con la Corona en el ordenamiento inglés), a otros en que se construyen mayores niveles de responsabilidad, especialmente en consideración a la persona del acreedor (como en los créditos derivados de las relaciones de familia o del derecho de daños). En esto, la lectura del legislador de 1929 fue claramente insuficiente, quizás porque, en su mente, la matriz estuvo dada por la figura del comerciante y la necesaria revisión de las obligaciones derivadas de su ejercicio profesional. Por otra parte, tampoco se indicaba

\footnotetext{
107 Palma (1940) p. 167.

108 Arcos (1929) p. 116 estimaba que, por la redacción de la norma, no era posible anular los efectos extintivos del sobreseimiento definitivo.

109 Gross (1999) pp. 110-113.
} 
la amplitud de los efectos de la extinción, especialmente en lo referente a los casos en que existieren codeudas solidarias o garantías otorgadas por terceros, cuestión que, en los expedientes comparados consultados, había quedado resuelto desde la ley inglesa de 1711. Esta inadvertencia, que, incluso llegó a una jurisprudencia a sostener la extinción de las codeudas solidarias ${ }^{110}$, impone una consecuencia indeseada, como es la completa traslación del riesgo al acreedor haciendo inoperantes las cauciones, reales o personales, conferidas por terceros en un escenario de insolvencia, que es precisamente uno de los riesgos que se intenta cautelar por su intermedio.

\section{CONCLUSIONES}

El cobro de las deudas cuando el deudor es insolvente es una empresa ciertamente difícil, especialmente en los casos en los que no se avistan verdaderos incentivos para que aquel incremente su patrimonio sabiendo, de antemano, que tales esfuerzos solo beneficiarán a sus acreedores. En tiempos en los que la quiebra se formulaba en un contexto claramente sancionatorio, incluso penalizado con la muerte, la emergencia del discharge en el ordenamiento inglés se presenta como una figura contradictoria, solo cobrando sentido si logra ser enmarcada en el diseño de incentivos, positivos y negativos, para que el deudor colaborase a fin de aumentar las posibilidades de pago en este calamitoso escenario. Esta formulación tutelar de los acreedores se justificaba también en la inexistencia de concursos voluntarios y en la necesidad de obtener su consentimiento mayoritario o, al menos, un pago parcial de la deuda. El tono solo cambió en la reformulación propuesta por las regulaciones estadounidenses, en que, dada la necesidad de enfrentar los riesgos del comercio (como asimismo de la conquista territorial), se vio en el concurso un medio de tutela del deudor, considerando al fracaso como parte normal de los procesos económicos. Con ello, el discharge se ofreció desligado de los intereses de los acreedores, permitiéndose, además, el inicio voluntario del concurso y erradicando cualquier consulta previa para su procedencia. El modelo se complementó bajo la idea de dar nuevas oportunidades al deudor honesto, pero desafortunado, de modo que la figura se ofreció con estrictos requisitos de procedencia que miraban a la conducta del sujeto y a la advertencia de ciertas deudas que no podían verse extinguidas al existir una política de protección considerada más relevante que el fresh start.

Del análisis del mensaje, de la discusión y del texto de la Ley No 4.558, de 1929, se observa que fue en este segundo espíritu con el que tempranamente se incorporó esta figura en el ordenamiento chileno. Más allá de los antecedentes textuales, se contextualiza en un modelo en que se admitió con soltura el inicio voluntario de la quiebra y en que la participación de los acreedores en la obtención del discharge era meramente reactiva al incumplimiento de los requisitos objetivos establecidos en el artículo 134. Ahora bien, esta formulación pecaba de ciertas inconsistencias en su comparación con los antecedentes tenidos a la vista, especialmente por la imbricación del reproche penal (diferente, además, para deudores civiles y comerciales), y de algunos vacíos derivados de la inadvertencia de la necesidad

110 BANCO DE CONCEPCIÓN CON ARREDONDO Y OTROS (1992). 
de acotar los efectos de la extinción de las obligaciones, en especial, en lo referente a deudas no descargables y a las garantías otorgadas por terceros.

\section{BIBLIOGRAFÍA CITADA}

Alarcón Cañuta, Miguel (2018): "La deuda por obligación constituida a través de crédito con aval del estado no constituye excepción al discharge en el ordenamiento jurídico chileno", Revista Chilena de Derecho Privado, No 31: pp. 9-59.

Arcos Riveros, Blanca (1929): De las quiebras en nuestro derecho (Santiago, Soc. Imprenta y Lit. Universo).

BlackWell, William (1766): Commentaries on the laws of England, Vol. II (Oxford, The Clarendon Press).

Brahm García, Enrique (2018): “Contra la corriente: la crítica conservadora -en lo político y económico- durante los primeros años del gobierno de Carlos Ibáñez del Campo (1927-1928)", Revista de Estudios Histórico-Jurídicos, vol. XL: 473-503.

Bravo K., Aníbal (1929): Ley No 4.558 sobre quiebras (Santiago, Imprenta Universitaria).

Bravo Rodríguez, Armando (1940): El sobreseimiento en las quiebras (Santiago, Benaprés y Fernández Limitada).

Boshroff, Douglass (1982): "Limited, conditional, and suspended discharges in AngloAmerican bankruptcy proceedings", University of Pennsylvania Law Review, vol. 131: pp. 69-125.

Caballero Germain, Guillermo (2018): "Sobreendeudamiento y exoneración legal de los saldos insolutos en el procedimiento concursal del consumidor", Ius Et Praxis, vol. 24, No 3: pp. 133-172.

Carlos, Ann y Lamping, Jennifer (2010): "Conformity and the certificate of discharge: Bankruptcy in early eighteenth century England". Disponible en eh.net/eha/wp-content/uploads/2013/11/Carlos.pdf. Fecha de consulta: 17 de agosto de 2019.

Carrasco Vásquez, Jorge (1963): Evolución del Derecho de quiebras en Chile (Santiago, Editorial Jurídica de Chile).

Cohen, Jay (1983): "The history of imprisonment for debt and its relation with the development of discharge in bankruptcy", The Law School Record, vol. 29: pp. 5-12.

Coleman, Peter J. (1974): Debtors and creditors in America. Insolvency, imprisonment for debt and bankruptcy, 1707-1900 (Madison, The Historical Society of Wisconsin).

Comparato, Guido (2018): The financialisation of the citizen (Oxford, Hart).

Countryman, Vern (1976): "A history of American Bankruptcy law", Commercial Law Journal, vol. 81, No 6: pp. 226-233.

Defoe, Daniel (1697): “Essay upon projects”. Disponible en: https://www.gutenberg.org/ files/4087/4087-h/4087-h.htm. Fecha de consulta: 17 de agosto de 2019.

Donoso Letelier, Crescente (1991-1992): "Libro copiador de telegramas del presidente Carlos Ibáñez” (1928-1931), Historia, Vol. 26: pp. 297-383.

Durán Bernales, Alberto (1945): Explicaciones y jurisprudencia de la Ley de Quiebras de Chile (Santiago, Talleres Gráficos Gutenberg). 
Goldenberg Serrano, Juan Luis (2016): "Mecanismos de protección a los acreedores de una sociedad de responsabilidad limitada infracapitalizada: análisis crítico y propuesta de solución”, Revista Chilena de Derecho Privado, No. 27: pp. 141-225.

Goldenberg Serrano, Juan Luis (2017): "La responsabilidad patrimonial universal y el sobreendeudamiento de la persona deudora”, en VV.AA., Estudios de Derecho Civil XII (Santiago, Thomson Reuters) pp. 239-255.

Goldenberg Serrano, Juan Luis (2018): "La evolución del Derecho concursal chileno", en Alcalde, Jaime y Embid, José Miguel (edit.), La Modernización del Derecho Mercantil (Madrid, Marcial Pons) pp. 591-606.

Gross, Karen (1999): Failure and forgiveness (New Haven / Londres, Yale University Press). Holdsworth, William (1966): A history of English law, Vol. VIII (Londres, Methuen \& Co Ltd / Sweet and Maxwell).

Hoppit, Julian (1987): Risk and failure in English business 1700-1800 (Cambridge, Cambridge University Press).

Huls, Nick (2011): "Consumer bankruptcy: a third way between autonomy and paternalism in private law", en VV.AA., Juxtaposing autonomy and paternalism in private law (Oxford y Portland, Hart).

JONES, W. J. (1979): “The foundations of English bankruptcy: statutes and commissions in the early modern period", Transactions of the American Philosophical Society, vol. 69, No 3: pp. 1-63.

KadENS, Emily (2010a): "The last bankrupt hanged: balancing incentives in the development of bankruptcy law", Duke Law Journal, vol. 59, No 7: pp. 1229-1319.

Kadens, Emily (2010b): "The Pitkin affair: a study of fraud in early English bankruptcy", American Bankruptcy Law Journal, vol. 84, No 4: pp. 483-570.

Kilborn, Jason (2007): Comparative consumer bankruptcy (Durham, Carolina Academic Press).

LeVInthal, Louis (1919): "Early history of English bankruptcy", University of Pennsylvania Law Review and American Law Register, vol. 67, No 1: pp. 1-20

McCoid, John (1996): "Discharge: the most important development in bankruptcy history", American Bankruptcy Law Journal, vol. 70, № 2: pp. 163-194.

Newton, Henry (1899): "United States Bankruptcy Law of 1898”, Yale Law Journal, vol. 9, No 7: pp. 287-296.

Noel, F. Regis (1919): A history of bankruptcy law (Washington D.C., Chas. H. Potter \& Co.).

Palma Rogers, Gabriel (1940): Legislación de quiebras (Santiago, Talleres Gráficos Samaniego).

Pérez Ragone, Álvaro (2013): "La progresiva humanización de los procesos de insolvencia de personas naturales: desde la servidumbre e infamia hasta los procesos concursales de consumidores", Revista de Derecho (Valparaíso), vol. 41, No 3: pp. 641-678.

Puelma Accorsi, Álvaro (1966): Curso de Derecho de quiebras (Santiago, Editorial Jurídica de Chile).

Puga Vial, Juan Esteban (1999): Derecho concursal. El juicio de quiebras, Tomo II (Santiago, Editorial Jurídica de Chile). 
Puga Vial, Juan Esteban (2016): Derecho concursal. Los delitos concursales (Santiago, Editorial Jurídica de Chile).

Pugh, Ralph B. (1968): Imprisonment in medieval England (Cambridge, Cambridge University Press).

Ramsay, Iain (2017): Personal bankruptcy in the XXI century. A comparative analysis of the US and Europe (Oxford y Portland, Hart).

Ripert, Georges (1936): "Le droit de ne pas payer ses dettes", Dalloz, Recueil Hebdomadaire de Jurisprudence, Chronicles: pp. 57-60.

Rudolph, Julia (2013): Common law and enlightment in England, 1689-1750 (Woodbridge, The Boydell Press).

SGARD, Jérôme (2013): "Bankruptcy, fresh start and debt renegotiation in England and France (17th to 18th Century)", en VV.AA., The History of Bankruptcy. Economic, social and cultural implications in early modern Europe (Oxfordshire, Routledge) pp. 223-235.

Skeel Jr., David A. (2001): Debt's dominion. A history of bankruptcy law in America (Princeton, Princeton University Press).

ТАВB, Charles Jordan (1991): "The historical evolution of the bankruptcy discharge", American Bankruptcy Law Journal, vol. 65, No 3: pp. 325-372

Veall, Donald (1970): The popular movement for law reform 1640-1660 (Oxford, The Clarendon Press).

\section{JURISPRUDENCIA CITADA}

BANCO de ConcepCión con ARRedondo y otros (1992): Corte Suprema, 16 de enero de 1992 (recurso de queja), Gaceta Jurídica No 141, pp. 95-97.

Hardie v. DRY Goods Co., 21 A. B. R. 457, 165 Fed. 588 (C.C.A. Tex.) 
